\title{
PROSES PRODUKSI WAX JENIS FULLY REFINED (FRW) DARI HARD SEMI REFINED (HSR) DALAM RANGKA MENINGKATKAN NILAI TAMBAH
}

\author{
Fauziati \\ Balai Riset dan Standardisasi Industri Samarinda
}

\begin{abstract}
ABSTRACK
Wax is solid material product and derivative product of natural oil processing. It has various level of smoothness, flexibility and melting point. PT. Pertamina Processing Unit (UP) $\vee$ Balikpapan is one of wax products in East Kolimantan. Indonesia. Pertamina produces 5 (five) types of wax which are Fully Refined Wax (FRW). Hard Hard Paper (HHP), Hard Semi Refined wax (HSR). Yellow Batik Wax (YBW) and Match Wax (MW). These waxes are produced by four steps processes like dewaxing, sweating, treating and molding.

In domestic purposes, HHP is used for the raw material of paper coating industry. HSR is used for the material of lighting wax products and for the raw moterial of another type of wax. FRW. Match Wax is used the row material of match processing, yellow batik wax is used for batik wax and FRW (export grade) is used for fruit coating industry. pharmacy and cosmetic. In the production of sweating with VTS (vertical tube stove), domestic grade is produced and it includes HHP. HSR. Match wax and yellow batik wax. The process of sweating with sweating box produces export grade wax and the result is Fully Refined Wax. (FRW).

The process of making Fully Refined Wax in the laboratory scalc uses HSR wax with $14 \%$ oil content, yellow to brown color and grasy, melting point $58^{\circ}-60^{\circ} \mathrm{C}$. This process includes de-oiling process (to reduce oil content) step by step (every 2 degrees) heating from the temperature $48^{\circ} \mathrm{C}$ to $58^{\circ} \mathrm{C}$ (melting point of oil). Therefore the change of color occurs from yellow to bright white. not oily and odorless like the type of FRW wax.
\end{abstract}

Keywords : wax, prosess production, utilization

\section{A. PENDAHULUAN}

Lilin (wax) merupakan benda padat produk turunan dari proses pengolahan minyak bumi yang mempunyai variasi derajad kehalusan dan kelenturan serta memiliki sifat fisik mudah meleleh. Lilin salah satunya dihasilkan di unit pengilangan minyak bumi PT Pertamina Unit Pengolahan (UP) $\vee$ di Balikpapan Kalimantan Timur .Unit Pengolahan (UP)V menghasilkan5 (lima) jenis lilin yakni Fully Refined Wax(FRW), Hard Hard paper (HHP), Hard Semi Refined (HSR) , Yellow Batik Wax (YBW) dan Match Wax (MW) dengan kapasitas produksi secara keseluruhan sebesar 23.904,09 ton/tahun ( Pertamina UP V Balikpapan .2003)

Lilin dikategorikan berdasarkan sumber dan proses pembentukannya menjadi natural wax, modified wax, synthetic wax, compounded wax.
Lilin dengan sifat fisika tak berwarna (putih) ,tanpa bau dan greasy merupakan hasil pemurnian campuran padatan hidrokarbon yang diperoleh dari minyak bumi. Dalam dunia industri, lilin dibedakan dalam berbagai grade berdasarkan variasi sifat fisika terutama titik leleh pada kisaran suhu $110-150^{\circ} \mathrm{F}\left(43.3-65.5^{\circ} \mathrm{C}\right)$. Kelima jenis lilin yang dihasilkan Pertamina UPV telah sesuai dengan grade lilin yang diperlukan yaitu grade wax domestik seperti hard Hard Paper (HHP), Hard Semi Refined Wax (HSR) , Yellow Batik Wax ( YBW)dan Match Wax dan grade wax ekspor berupa jenis Fully Revined Wax (FRW). Lilin pada awalnya, merupakan hasil samping dari proses dewaxing dalam rangkaian produksi minyak pelumas, namun dengan meluasnya pemakaian lilin maka pengembangan produksi nya menjadi sangat menguntungkan. 
Lilin jenis hard semi refined digunakan sebagai bahan baku produk lilin penerang. dekoratif dan dapat digunakan sebagai bahan baku pembuatan lilin jenis fully refined, lilin jenis match wax digunakan sebagai bahan baku pembuatan korek api yang diproduksi dalam bentuk curah, lilin jenis yellow batik digunakan sebagai bahan baku pembuatan lilin batik dan diproduksi dalam bentuk slab, lilin jenis hard hard paper digunakan sebagai bahan baku industri pelapis kertas dan bahan baku pembuatan lilin jenis fully refined wax. Lilin jenis fully refined wax diproduksi dalam bentuk bulk dan slab, lilin jenis ini digunakan sebagai bahan baku coating buah,kosmetik dan semir sepatu .

\section{B. Proses Pembuatan lilin Jenis Hard Semi Refined (HSR) dan Fully Refined (FRW) Skala Pabrik}

Proses Pembuatan lilin jenis HSR atau FRW atau lilin secara umum ada 4 (empat) tahapan yang dilakukan yakni Dewaxing,Sweating. Treaiting dan moulding.

\section{Proses Dewaxing}

Dewaxing adalah proses pemisahan kandungan wax dari Paraffinic Oil Distillate (POD) dengan hasil yang disebut sebagai slack wax. Teknologi proses dewaxing adalah proses dewaxing dengan menggunakan solvent (larutan) dan proses dengan chilling-pressing.

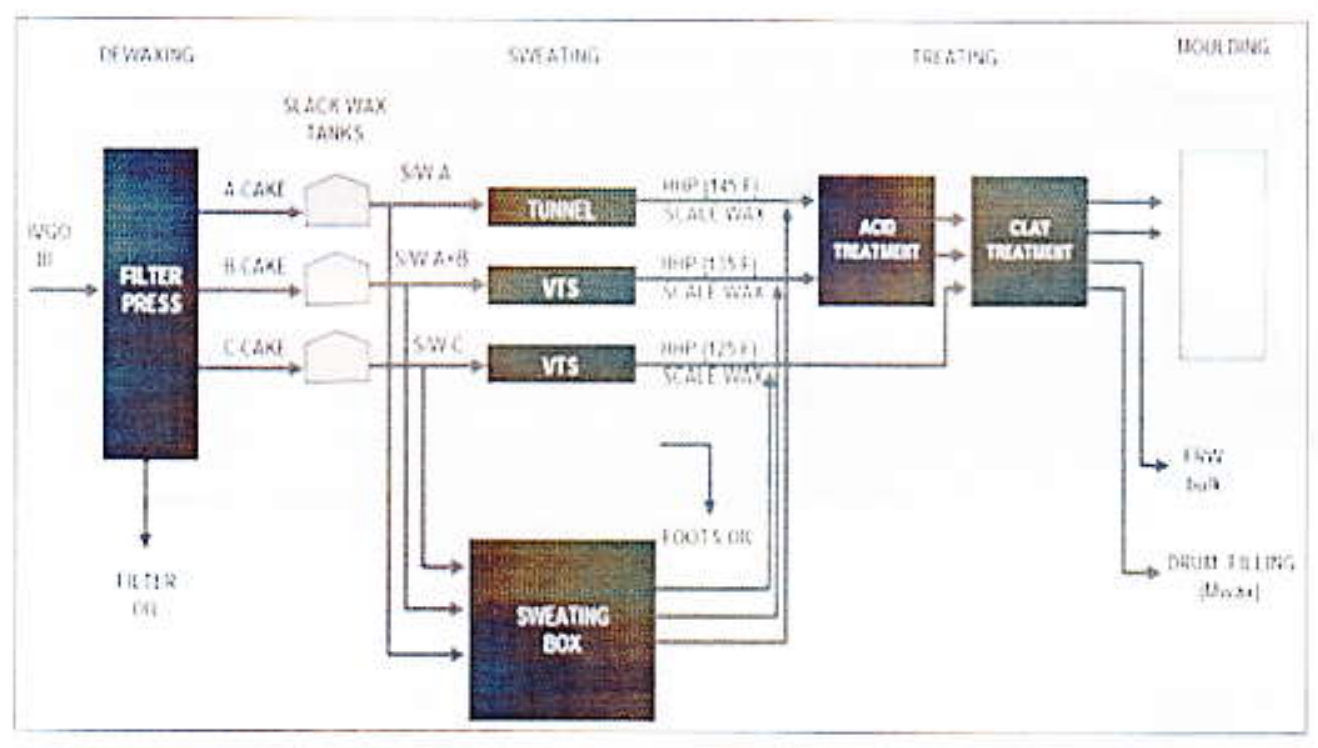

Gambar 1. Process Flow Diagram Wax Plant PT. Pertamina (Persero) UP V Balikpapan

Proses dewaxing dengan chilling-pressing adalah tipe proses yang sederhana menggunakan proses pendinginan umpan dan proses filtrasi bertekanan untuk memisahkan kristal paraffin. Pemisahan berbagai grade kristal paraffin secara umum didasarkan pada perbedaan sifat melting point dengan pengaturan pendinginan proses dewaxing

Di pabrik lilin di PT. Pertamina (Persero) UP $\vee$ Balikpapan, bahan baku paraffinic oil distillate dihasilkan dari Unit Distilasi Vacuum (HVU-III) dan berasal dari pengolahan Minyak Mentah Parafinis. Mode operasi proses ini secara batch pada setiap tahapan proses dan POD diumpankan secara batch ke masing-masing Filter Press setelah mengalami proses pendinginan pada unit chiller. Proses penyaringan (filter press) dewaxing berlangsung secara bertingkat (3-seri) pada kondisi operasi (temperature) yang berbeda untuk mendapatkan grade slack wax yang berbeda.

Chilling unit berupa double pipe exchanger yang dilengkapi scrapper dengan media pendinginan refrigeration system menggunakan refrigerant gas amoniak $\left(\mathrm{NH}_{3}\right)$ yang berfungsi untuk mendinginkan umpan ke filter press pada masing-masing tingkat pendinginan filter press. Fungsi chiller selain sebagai alat pendingin juga untuk mengkristalkan wax sebelum dipisahkan dalam filter press.

Pada Filter Press A (Gambar 1) dengan temperatur feed $\pm 30^{\circ} \mathrm{C}$ akan dihasilkan A-Cake 
dan Filtrat A Filter Oil sebagai feed B-Filter Press dengan pendinginan pada temperatur $\pm 20^{\circ} \mathrm{C}$ akan dihasilkan B-Cake dan Filtrat B Filter Oil. B Filter Oil sebagai feed C-Filter Press didinginkan pada temperatur $\pm 10^{\circ} \mathrm{C}$ dan dihasilkan C-Cake dan C Filter Oil. Masing-masing Cake yang dihasilkan dari filter press dicairkan pada melting box untuk selanjutnya disimpan pada slack wax tank dalam kondisi cair. C-Filter Oil ditampung di tanki dan selanjutnya digunakan sebagai campuran feed unit hydrocracker. Untuk mempersiapkan feed pada proses selanjutnya (sweating) proses ini dilengkapi dengan fasilitas blending untuk pencampuran cake sesuai target grade produksi.

\section{Proses Sweating}

Sweating adalah proses dengan pemanasan secara bertahap terhadap slack wax untuk menurunkan oil content dengan hasil yang disebut dengan scale wax. Proses sweating umumnya didasarkan pada hasil percobaan dan pengalaman Proses ini merupakan proses pengurangan kandungan minyak dengan prinsip kesetimbangan fase antara cair-padat (proses rekristalisasi).

Efek pengurangan kandungan minyak terjadi karena kadar minyak dalam fase liquid lebih tinggi dibandingkan dalam fase padat, selanjutnya proses dengan titik lelehnya akan memisahkan kandungan minyak dari padatan slack wox. Pemanasan secara bertahap (gradually) padatan slack wax akan mencair sesuai dengan titik lelehnya bersamaan dengan kandungan minyak dipisahkan sehingga didapatkan lilin dengan titik leleh lebih tinggi.

Fasilitas proses sweating di wax plant UP-V terdiri dari Vertical Tube Stove (VTS) yang dioperasikan untuk grade lilin domestic dan sweoting box untuk grade ekspor dengan prinsip proses yang pada dasarnya sama. Proses sweating berlangsung secara batch dengan jumlah umpan sesuai kapasitas alat. Tahapan proses secara umum terdiri dari (a) water filling, (b) slack wax filling. (c) cooling, (d) sweating (gradually heating) dan (e) melting. Untuk proses cooling dan heating dilengkapi dengan sistem sirkulasi air dingin dan cooling tower system dan sirkulasi air panas dengan sumber pemanasan berasal dari steam.

\section{a. Proses Sweating dengan VTS (Vertical Tube Stove)}

Vertical Tube Stove (VTS) adalah berupa tabung silinder tegak dilengkapi dengan pipa-pipa yang berfungsi sebagai media perpindahan panas dengan mengalirkan cooled water pada saat cooling dan warm water dengan injeksi steam pada tahap heating (sweating). Bagian shell vertical tube stove diisi dengan slack wax yang pada bagian bawahnya dilengkapi dengan perforated plate berfungsi sebagai penahan solid slack wax selama proses sweating berlangsung. Kapasitas masing-masing vertical tube stove sebesar \pm 40 ton slack wax per batch.. Slack wax dipompakan masuk ke shell vertical tube stove hingga penuh dan dilanjutkan pendinginan dengan mensirkulasikan air pendingin ke dalam tubes hingga temperature pembekuan sempurna $( \pm 7$ jam). Proses sweating dimulai dengan sirkulasi air panas dan injeksi steam untuk menaikkan temperature slack wax secara bertahap dengan kenaikan $\pm 2{ }^{\circ} \mathrm{C}$ per jam hingga target temperature $45^{\circ} \mathrm{C}$ dan selanjutnya kenaikan temperature $\pm 1{ }^{\circ} \mathrm{C}$ per jam hingga didapatkan produksi scale wax.

Pemanasan menyebabkan terbentuknya oil pada permukaan wax. Oil dan lower melting point wax akan terdrain dengan kenaikan temperatur. Lelchan pada tahap pemanasan diambil sebagai foots oil dan recycle oil dengan pedoman hingga specific gravity 0,7800 . Berdasarkan analisa specific gravity tersebut, melting point \& oil content proses sweating dihentikan dan selanjutnya dilakukan proses melting untuk diambil sebagai produk scale wax (dengan pemanasan sampai dengan $80^{\circ} \mathrm{C}$ ).

Waktu siklus (cycle time) pengoperasian vertical tube stove tiap batch berkisar - 26 jam dengan yield produksi berkisar $37,5 \%$.

\section{b. Proses Sweating dengan Sweating Box}

Prinsip proses sama dengan vertical tube stove (dengan kapasitas 300 kilo-liter per batch.Alat proses ini terdiri dari 2 buah sweating box untuk memproduksi fully refined wax grade (ekspor). Sweating box dilengkapi sistim kendali instrumentasi (sequence program) yang lebih baik dan akurat dibandingkan dengan vertical tube stove. Bentuk peralatan utama berupa vessel box yang dilengkapi koil sirkulasi pendinginan dan 
pemanasan, perforated plate dan 2 buah ruang. Untuk keperluan pendinginan dilengkapi fasilitas sirkulasi air dingin dan cooling tower. Untuk keperluan pemanasan dilengkapi fasilitas sirkulasi air panas dengan injeksi steam pada hot water tank.

Pengisian slack wax didahului dengan pengisian air hingga batas di atas perforated plate (hal yang perlu diperhatikan adalah analisa melting point umpan sebagai set point program / controller). Kecepatan aliran pengisian slack wax dijaga $+50 \mathrm{~m}^{3}$ per jam untuk menghindari terjadinya ketidak seimbangan di 2 ruang dari sweating box. Proses pendinginan dengan sirkulasi air dingin hingga mencapai target (melting point $10^{\circ} \mathrm{C}$ ), dipastikan dengan drain water telah bebas minyak atau wax

Pedoman akhir proses sweating didasarkan pada analisa specific gravity, melting point, dan oil content dari foots oil. Pengambilan produk scale wox dilakukan dengan proses melting hingga semua scale wax di keluarkan ke tangki scale wax.

\section{Proses Treating}

Proses treating produksi wax yang cukup dikenal luas adalah tipe acid clay dan hydrotreating. Acid clay treating melibatkan proses yang sederhana dan efektif, namun adanya kerugian (losses) hasil reaksi, pemakaian asam sulfat pekat dan ekses buangan limbah sludge yang bersifat asam harus dipertimbangkan dalam aplikasinya.

Wax hydrotreating memiliki kelebihan berupa proses kontinyu katalitis, yield maximum, tanpa ckses lingkungan. Tujuan proses treating adalah stabilisasi kualitas produk wax dengan menghilangkan senyawa-senyawa hydrocarbon paraffin yang tidak diinginkan seperti cyclo, aromat dan senyawa hydrocarbon tidak jenuh.

\section{Proses Flow Diagram Wax Hydrotreating Unit}

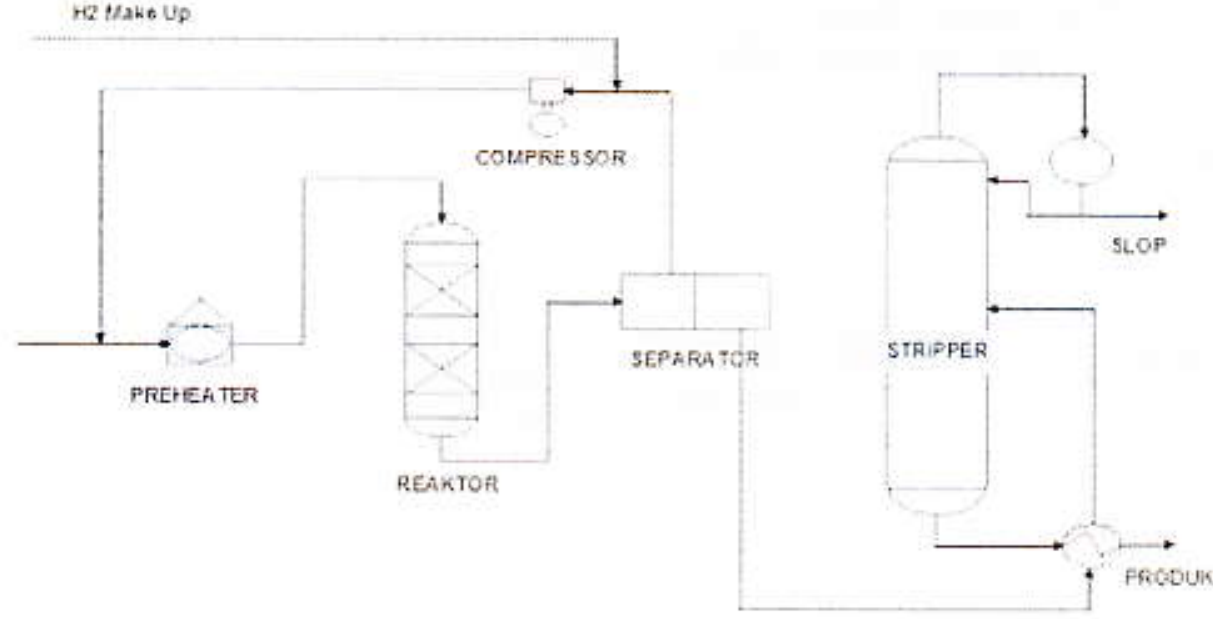

Gambar 2. Process Flow Diagram Wax Hydrotreating Unit

\section{Teknologi Proses Acid-Clay Treating}

Aplikasi proses treating wax dengan acid clay melibatkan pemakaian $\mathrm{H}_{2} \mathrm{SO}_{4}$ pekat dengan konsentrasi minimum 98\%. Pengenceran $\mathrm{H}_{2} \mathrm{SO}_{4}$ dengan adanya air akan menyebabkan korosi akibat reaksi ionisasi membentuk ion $\mathrm{SO}_{4}{ }^{-}$dan bereaksi dengan metal.

Rangkaian proses berlangsung pada 2 vessel agitator asam dan agitator clay yang beroperasi secara batch. Umpan scale wax yang telah bebas air dipompakan ke vessel agitator asam sejumlah kapasitas agitator ( \pm 14 ton per batch). Penambahan $\mathrm{H}_{2} \mathrm{SO}_{4}$ dilakukan secara 2 tahap :

- Tahap I ditambahkan sebanyak 11.5 liter; pengadukan 10 menit, settling 30 menit dan drain acid sludge.

- Tahap 2 penambahan $\mathrm{H}_{2} \mathrm{SO}_{4}$ dengan total $\pm 2.5 \%$ on feed, pengadukan I jam, settling 3 jam dan drain acid sludge. 
Sisa $\mathrm{H}_{2} \mathrm{SO}_{4}$ yang tidak bereaksi dinetralkan dengan penambahan kapur $\quad r \quad 0.5 \%$ dengan proses pengadukan,settling dan drain.

Penambahan clay untuk grade fully refined wax sebanyak $2 \times$ lipat yaitu $2 \%$ dibandingkan untuk grade domestik seperti hard hard paper. hard semi refined, yellow batik wax dan match wax sebesar $1 \%$ dengan pengadukan selama 1.5 jam pada temperatur $100-135{ }^{\circ} \mathrm{C}$ dengan pemanasan steam coil.

Proses akhir dari treating adalah penyaringan partikel padat( sisa clay) pada saat pemompaan / rundown produksi melalui clay filter press dengan menggunakan kain kanvas dan kertas saring.

Proses treating untuk grade batik wax dilakukan tanpa menggunakan asam sulfat (acid treating), sedangkan untuk grade match wax dilakukan dengan 2 kali acid treating.

\section{Proses Moulding / Finishing}

Pada dasarnya proses produksi wax berakhir setelah proses treating, sedangkan moulding lebih ditujukan untuk finishing dan handling. Beberapa unit produksi telah mengaplikasikan proses moulding untuk menyiapkan final wax product seperti lilin (candles) langsung dipasarkan kepada konsumen. Proses moulding kebanyakan lebih bersifat untuk tahap intermediate product dengan tujuan keleluasaan konsumen untuk produksi lanjutan.

Fasilitas di Kilang UP-V Balikpapan berupa moulding machine untuk memproduksi wax dalam bentuk lempengan (slab). Grade wax ekspor di produksi dalam bentuk bulk dan slab fully refined wax.

Tabel 2. Spesifikasi Produksi Wax Plant UPV

\begin{tabular}{|c|c|c|c|c|c|c|c|}
\hline \multirow{3}{*}{ Property } & \multicolumn{7}{|c|}{ Spesifikasi Produksi Wax Plant UP.V } \\
\hline & \multicolumn{7}{|c|}{ (Grade Produksi) } \\
\hline & HHP & HSR & MW & BW & $\begin{array}{l}\text { FRW } \\
125 \mathrm{P}\end{array}$ & FRW I 35P & FRW I 45P \\
\hline Color Saybolt & $\begin{array}{l}+30 \\
\mathrm{~min}\end{array}$ & $\begin{array}{l}+30 \\
\min \end{array}$ & $\begin{array}{l}+30 \\
\min \end{array}$ & - & $+30 \mathrm{~min}$ & $+30 \mathrm{~min}$ & $+30 \mathrm{~min}$ \\
\hline Thermal stability $170^{\circ} \mathrm{C}, 05$ haour & - & $\cdot$ & . & $\cdot$ & $+30 \mathrm{~min}$ & $+30 \mathrm{~min}$ & $+30 \mathrm{~min}$ \\
\hline Odor, D 1833 & $\operatorname{Max} 2$ & $\operatorname{Max} 2$ & $\operatorname{Max} 2$ & $\operatorname{Max} 2$ & None & None & None \\
\hline Appearance & White & White & White & - & White & White & White \\
\hline Melting Point, ${ }^{\circ} \mathrm{C}$ & 62.2 & $58.9-60.0$ & 46.1 & $\begin{array}{l}58.9 \\
60.0\end{array}$ & $53.3-54.4$ & $58.9-60.0$ & $62.8-63.9$ \\
\hline Oil Content, $\%$ mass & 14 & 18 & 40 & $18-20$ & $0.50 \mathrm{Max}$ & $0.50 \mathrm{Max}$ & $0.50 \mathrm{Max}$ \\
\hline \multicolumn{8}{|l|}{ Penetration $100 \mathrm{gr}$} \\
\hline $5 \sec @ 25^{\circ} \mathrm{C}$ & - & - & - & - & $25 \mathrm{Max}$ & $\therefore$ & $=$ \\
\hline $5 \sec @ 35^{\circ} \mathrm{C}$ & - & - & - & - & - & $25 \operatorname{Max}$ & $22 \mathrm{Max}$ \\
\hline
\end{tabular}

\section{c. Proses Pembuatan Lilin Jenis Fully Refined Wax (FRW) Skala Laboratorium .}

Bahan baku yang digunakan untuk membuat wax dengan jenis fully refined wax adalah wax jenis hard semi refined atau hard hard paper.Proses pembuatan lilin jenis FRW dengan menggunakan bahan baku lilin jenis HSR atau HHP dengan mengurangi kandungan minyak berdarkan pada titik lelehnya. Pada penelitian skala laboratorium digunakan bahan baku jenis hard semi refined (HSR) bahan bakunya mudah diperoleh di pasaran dan biasanya digunakan sebagai bahan lilin penerang olch dan dijual untuk kepentingan umum/masyarakat.

Wax jenis hard semi refined tersebut adalah termasuk grade wax domestik selain wax jenis hard hard paper, yellow batik wax dan match wax. diproduksi melalui tahapan proses dewaxing (pemisahan wax dari paraffinic oil distillate), sweating (proses pengeringatan atau pemanasan bertahap / deoiling), treating (proses pemurnian wax) dan molding (pencetakan).

Wax jenis Fully Refined Wax (FRW) merupakan grade kualitas ekspor yaitu jenis FRW 135 P dan FRW 145P, sedangkan untuk FRW 
125P adalah wax dengan grade ekspor yang digunakan sebagai bahan kosmetik dan semir sepatu.

Pada penelitian skala laboraorium digunakan bahan baku jenis hard semi refined untuk pembuatan wax jenis fully refined wax. Hard semi refined adalah spesifikasi produk wax yang mempunyai kandungan minyak sebesar 14 $\%$, titik leleh berkisar antara $58,9-60,0{ }^{\circ} \mathrm{C}$. Sedangkan fully refined wax adalah jenis wax kualitas ekspor yang mempunyai kandungan minyak sebesar maksimal $0,5 \%$ dan titik leleh berkisar $53,3-63.9{ }^{\circ} \mathrm{C}$ biasanya digunakan sebagai bahan baku coating

Proses pembuatan wax jenis fully refined wax skala laboratorium dengan menggunakan bahan baku wax jenis hard semi refined adalah :

1. Menimbang wax jenis hard semi refined dengan berat $-60 \mathrm{gr}$

2. Dilakukan proses sweating (pengeringatan/pengurangan

kandungan oil) dengan jalan melakukan pemanasan pada titik leleh minyak dalam wax yaitu $48 \quad 58{ }^{\circ} \mathrm{C}$ sampai permukaan lilin tidak timbul keringat lagi, pada suhu konstant dengan menggunakan water bath.

3. Pada saat permukaan wax berkeringat dan mengeluarkan minyak, minyak diambil / dituang atau diserap dengan menggunakan kapas.
4. Proses pemanasan pada suhu tersebut diatas dilakukan selama 7 sampai dengan -12 jam.

5. Setelah minyak keluar semua dari permukaan lilin, kemudian didinginkan dan ditimbang untuk mengetahui rendemen wax yang tertinggal.

6. Lilin yang dihasilkan kemudian di analisa terhadap parameter uji yaitu kandungan minyak, titik leleh dan warna yang disesuaikan dengan standar apakah wax tersebut termasuk jenis FRW I25P, FRW I35P atau FRWI 45P

Pada penelitian ini dibuat wax jenis fully refined wax dari wax jenis hard semi refined dengan memvariasi waktu pemanasan yaitu 8 jam, 10 jam, 12 jam dan 15 jam dan sebagai kontrol digunakan wax jenis hard semi refined

Variasi waktu pemanasan jenis wax Hard Semi Refined (HSR) adalah:
$A=$ Wax jenis HSR dengan waktu pemanasan selama 8 jam
$B=$ Wax jenis HSR dengan waktu pemanasan selama 10 jam
$C=$ Wax jenis HSRdengan waktu pemanasan selama 12 jam
$D=$ Wax jenis HSR dengan waktu pemanasan selama $15 \mathrm{jam}$
$E=$ Wax jenis HSR tanpa perlakuan (sebagai kontrol)

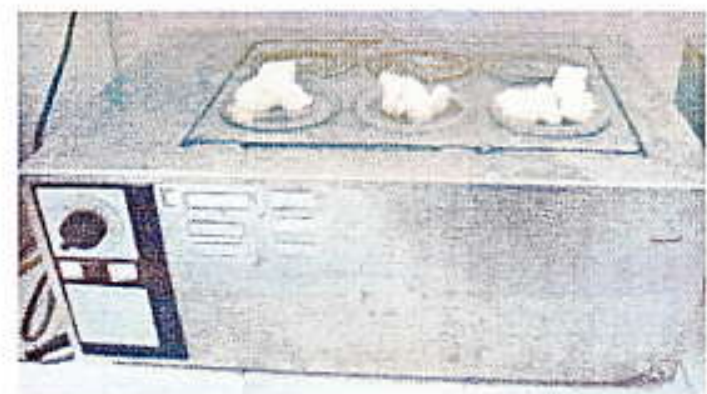

Gambar 3. Proses Sweating Wax (penguranan kandungan minyak) jenis Lilin HSR

Bahan baku proses pembuatan wax jenis fully refined wax pada penelitian skala laboratorium adalah wax jenis hard semi refined yang dibeli di pasaran umum (koperasi UKM di Balikpapan, biasanya digunakan oleh pengrajin sebagai lilin penerang dengan spesifikasi warna kuning, greesy (berbau lemak) dan bila dipegang berminyak dengan titik leleh berkisar $58-60^{\circ} \mathrm{C}$ dan kandungan minyak $14 \%$.

Pada pembuatan wax jenis fully refined dibuat dengan jalan memanaskan lilin Hard 
Semi Refined (HSR) secara bertahap dari temperatur $48{ }^{\circ} \mathrm{C}$ sampai dengan $58{ }^{\circ} \mathrm{C}$ (temperatur titik leleh minyak) dan pada saat mencapai suhu $48^{\circ} \mathrm{C}$ dalam keadaan konstan secara bertahap setiap 30 menit dinaikkan suhunya $-2{ }^{\circ} \mathrm{C}$, minyak mulai keluar dari wax -1 jam setelah mencapai suhu konstan $48{ }^{\circ} \mathrm{C}$. Dengan kenaikan suhu dan lamanya waktu pemanasan, sehingga terjadi perubahan warna wax semula berwarna kuning menjadi putih mengkilat setelah didinginkan, tidak berminyak dan tidak berbau minyak.

Tabel 4. Hasil Analisa Lilin

\begin{tabular}{|c|c|c|c|c|c|c|c|c|c|}
\hline \multirow{2}{*}{ No } & \multirow{2}{*}{ Parameter } & \multirow{2}{*}{ Satuan } & \multirow{2}{*}{ Merode } & \multirow{2}{*}{ Spesifikasi } & \multicolumn{5}{|c|}{ Hasil Pengujian } \\
\hline & & & & & A & B & C & D & $E$ \\
\hline 1. & Oil Content & $\%$ wt & ASTM & Mak. 0.5 & 1,93 & 1.05 & 0,85 & 0,56 & 14 \\
\hline 2. & $\begin{array}{l}\text { Melting } \\
\text { point }\end{array}$ & ${ }^{\circ} \mathrm{C}$ & ASTM & 58 & 61 & 61.5 & 62 & 63 & 58 \\
\hline 3. & Rendemen & $\%$ & SNI & - & 82 & 76 & 70 & 60 & - \\
\hline 4. & Warna & - & Visual & Putih & Puth & $\begin{array}{l}\text { Putih } \\
\text { bersih }\end{array}$ & Putih bersih & $\begin{array}{c}\text { Putih } \\
\text { Menglilap }\end{array}$ & Kuning \\
\hline 5. & Bau & . & Visual & $\begin{array}{c}\text { Tak } \\
\text { berbau }\end{array}$ & $\begin{array}{c}\text { Tak } \\
\text { berbau }\end{array}$ & Tak berbau & Tak berbau & Tak berbau & Berminyak \\
\hline
\end{tabular}

Sumber : Fauziati dkk

Pada penelitian pembuatan wax fully refined wax dari bahan baku wax jenis hard semi refined dengan kandungan oil sebesar $14 \%$, warna putih kekuningan, gressy (berminyak). Kemudian dilakukan pemanasan pada titik leleh (melting point) minyak berkisar antara $48{ }^{\circ} \mathrm{C}$ sampai dengan $58{ }^{\circ} \mathrm{C}$ dengan variasi waktu pemanasan jenis wax HSR adalah

$$
\begin{aligned}
A= & \text { Wax jenis HSR dengan waktu } \\
& \text { pemanasan selama } 8 \text { jam } \\
B= & \text { Wax jenis HSR dengan waktu } \\
& \text { pemanasan selama } 10 \text { jam } \\
C= & \text { Wax jenis HSR dengan waktu } \\
& \text { pemanasan selama } 12 \text { jam } \\
D= & \text { Wax jenis HSR dengan waktu } \\
& \text { pemanasan selama I5 jam. }
\end{aligned}
$$

Dari hasil penelitian menunjukkan bahwa jenis wax hard semi refined (A) dengan waktu pemanasan selama 8 jam diperoleh rendemen $82 \%$, kandungan oil sebesar $1,93 \%$ dan titik leleh (melting point) wax setelah dipanaskan sebesar $61^{\circ} \mathrm{C}$, dengan warna putih dan sedikit berbau minyak.

Jenis wax hard semi refined (B) dengan waktu pemanasan selama 10 jam diperoleh rendemen $76 \%$, kandungan oil sebesar $1,05 \%$ dan titik leleh (melting point) wax setelah dipanaskan sebesar $61,5^{\circ} \mathrm{C}$, dengan warna putih dan sedikit berbau minyak. Untuk jenis wax hard semi refined (C) dengan waktu pemanasan selamal2 jam diperoleh rendemen $70 \%$, kandungan oil sebesar $0,85 \%$ dan titik leleh (melting point) wax setelah dipanaskan sebesar $62^{\circ} \mathrm{C}$, dengan warna putih bersih dan tak berbau minyak. Sedangkan untuk jenis wax hard semi refined (D) dengan waktu pemanasan selama 15 jam diperoleh rendemen $60 \%$. kandungan oil sebesar $0,56 \%$ dan titik leleh (melting point) wax setelah dipanaskan sebesar $63^{\circ} \mathrm{C}$, dengan warna putih mengkilap dan tak berbau minyak.

Spesifikasi wax yang dipersyaratkan untuk wax jenis fully refined wax secara keseluruhan adalah kandungan oil maksimal $0,5 \%$, melting point $59^{\circ} \mathrm{C}$ dan warna putih. Dari 4 (empat) jenis wax Hard Semi Refined tersebut diatas hanya jenis wax hard semi refined (D) yang masuk dalam kriteria spesifikasi wax jenis fully refined wax walaupun kandungan oilnya sedikit diatas maksimal yang dipersyaratkan yaitu $0,56 \%$, sedangkan melting point dan warna serta bau sesuai dengan yang dipersyaratkan. Hal tersebut menunjukkan bahwa semakin lama waktu pemanasan pada titik leleh (melting point) 48 $58{ }^{\circ} \mathrm{C}$ dalam keadaan konstant maka rendemen wax yang dihasilkan semakain kecil, kandungan oil semakin kecil dan titik leleh (melting point) wax semakin tinggi sedangkan melting poin wax jenis fully refined wax adalah $59 \quad 70^{\circ} \mathrm{C}$. 
Berdasarkan teori dan pengalaman proses dipabrik bahwa wax jenis fully refined wax yang dihasilkan dengan kualitas sesuai dengan tabel 2 spesifikasi produk wax plant UP V. baik FRW 125P, FRW 135P dan FRW 145 dilakukan pemanasan selama $r 26$ jam untuk memperoleh wax jenis fully refined waxdengan oil content, minimum $(0,5 \%)$ dan melting point tinggi sesuai standar yang dipersyaratkan tetapi rendemen yang diperoleh relatif lebih kecil.(37,5\%) dari bahan baku wax (Scale wax)

\section{d. Kegunaan $\mathbf{W}-\mathbf{x}$ Jenis Fully Refined Wax (FRW )}

Fully Refined Wax (FRW) yang dihasilkan dari proses skala laboratorium berasal dari bahan baku wax jenis HSR (Hard Semi Refined) yang diproduksi skala pabrik melalui 4 (empat) tahapan proses yaitu Dewaxing ,Sweating ,Treating dan Moulding . Fully Refined wax yang dihasilkan tersebut dapat digunakan sebagai bahan baku pembuatan coating, cosmetik dan semir sepatu .

\section{KESIMPULAN}

Pada proses pembuatan lilin jenis Fully Refined Wax (grade wax ekspor) skala laboratorium dibuat dari jenis wax HSR dengan kandungan oil sebesar $14 \%$ warna kuning sampai dengan kecoklatan greesy (berminyak) melting point $58-60^{\circ} \mathrm{C}$, melalui proses deoling (pengurangan kandungan minyak) dengan pemanasan secara bertahap dari temperatur $48^{\circ} \mathrm{C}$ sampai dengan $58^{\circ} \mathrm{C}$ (temperatur titik leleh minyak) dengan kenaikan suhu dari $48^{\circ} \mathrm{C}$ menjadi $58^{\circ} \mathrm{C}$ yang dilakukan secara bertahap dimulai dengan pemanasan dengan kenaikan suhu $\pm 2{ }^{\circ} \mathrm{C}$ dan waktu pemanasan selama 15 jam sehingga terjadi perubahan warna dari kuning menjadi putih mengkilap tidak berminyak dan tidak berbau sehingga diperoleh kandungan minyak sebesar $0,56 \%$ dan randemen sebesar $60 \%$ sedang standard nya adalah sebesar $0,50 \%$ Dengan melalui proses produksi tersebut dapat meningkatkan nilai tambah bagi UKM yang memproduksinya, kualitas jenis wax dari jenis HSR menjadi FRW

\section{DAFTAR PUSTAKA}

Fauziati dkk, 2006. Pemanfaatan Wax sebagai Cooting Buch , Baristand Industri Samarinda , 2006

NPRC, 1998 . Develovement of the Box-Type Sweoting Unit, NOC Technical Service Agreement document. NPRC Yokohama Refinery.

NPRC, 1999, Wax Hydrotrating Technical Proposal, NigataConstruction, Japan . Rochman Syaiful, 2006, Sekilas Wax Plant, WWW, pertamina -up5, Com .

Anonim, 1993. Standard Test Method For Oil Content OfPetrolium Wax, ASTMIP.

Anonim , 1993, Standard Test Method For Melting Point Of Petrolium Waxes, ASTM -IP .1993. 